\title{
Breast cancer in young women: A retrospective study from tertiary care center of north India

\author{
Deepti Sharma, Garima Singh
}

\begin{abstract}
Aim: Breast cancer is the most common cause of cancer in women worldwide. They have more aggressive clinical behaviour with poor outcomes in younger patients. The aim of this study was to evaluate the impact of age on prognosis of breast cancer in women above and under 40 years of age. Material and Methods: Medical record of 415 patients with invasive breast cancer were analysed from January 201 I to December 2014 in our department. The last was done in December 20I5.All cases diagnosed with breast cancer stages I to IV were evaluated, and grouped on the basis of age [less than 40 and above 40 years].Baseline categorical variables were analysed using the Chi-square test or Fisher's exact test. Non categorical variable were analysed using $t$-test. Result: A total of 372 patients were reviewed because 42 patients defaulted. The median age at the time of diagnosis was 44.6 years (range 23 to 90 years). Metastasis to distant organs were more in women with age <40. Tumour relapse occurred in I3I cases, among which 84 cases died, 35 patients $(26.31 \%)$ in less than 40 group vs.49 patients (20.50\%) in above 40 groups. The estimated median OS in the two groups are 32 and 41 months respectively. Conclusion: The biological behaviour of breast cancer in younger age group has been shown to be associated with aggressive nature and has a worse clinical outcome as compared to that in older group.
\end{abstract}

Key words: Breast cancer, metastasis, poor prognosis, young age

\section{Introduction}

Breast cancer is the most common cause of cancer in women worldwide. Especially it is a disease of postmenopausal and elderly age group, approximately $5.6 \%$ of breast cancer patients are $\leq 40$ years. $^{[1]}$ They are characterized by less hormone sensitivity, higher human epidermal growth factor receptor 2 expressions, aggressive clinical behavior with poor outcomes as compared to the elderly group. ${ }^{[2,3]}$

Aim

The aim of this study was to evaluate the impact of age as an adverse factor in the presentation, recurrence, and prognosis of breast cancer in women above and under 40 years of age.

\section{Materials and Methods}

We analyzed medical records of 415 patients diagnosed with invasive breast cancer from January 2011 to December 2014 in our hospital. A total of 42 patients were excluded as they did not turn up for any treatment. Finally, 372 patients were analyzed. The last follow-up of all patients was done in December 2015. All cases diagnosed with breast cancer Stages I-IV were evaluated. The patients were then grouped on the basis of age $<40$ and above 40 years of age, both groups were compared regarding the clinical presentation and the modality of treatment they received. Additional exclusion criteria were any therapy before diagnosis (surgery/radiotherapy/chemotherapy), previous history of malignancy and history of any other medical illness, which would otherwise limit the survival of the patient in the absence of malignancy. All patients underwent standard treatment modalities (neoadjuvant or adjuvant chemotherapy, radiotherapy, chemoradiation, and/or surgery: modified radical mastectomy, breast conservation surgery, toilet mastectomy depending on the stage of presentation [Table 1].

\section{Statistical analysis}

Overall survival (OS) was defined as the time period from diagnosis to death from any cause. Disease-free survival (DFS)

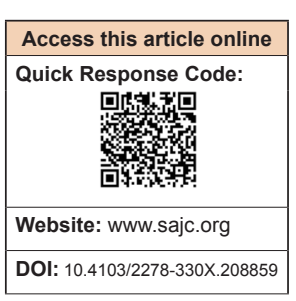

Department of Radiation Oncology, VMMC and Safdarjung Hospital, New Delhi, India Correspondence to: Dr Deepti Sharma, E-mail: drdeeptisharma 16@gmail.com was defined as the time period from diagnosis to the first locoregional or distant recurrence. The patients who did not experience any event/death or were lost to follow-up were censored for survival analysis. Baseline categorical variables were analyzed using Chi-square and Fischer's exact tests. Non-categorical variable was analyzed using $t$-test. DFS and OS curves were calculated using the Kaplan-Meier method. Log-Rank test was used to calculate OS and DFS. $P<0.05$ was considered statistically significant.

\section{Results}

A total of 372 patients were reviewed. The median age at the time of diagnosis was 44.6 years (range $23-90$ years) [Table 1]. Out of which 133 were $<40$ years $(33.07 \%)$. A total of 353 patients were diagnosed with Stages II and III (125 in under 40 group and 228 in above 40 years age group). $66.16 \%$ of patients $<40$ group belong to Stage III as compared to $54.4 \%$ of patients in above 40 group ( $P=0.029$, significant). A total of 12 patients presented with metastasis at the time of diagnosis (4 and 8 patients, respectively) in two groups. In $<40$ group 96 patients $(72.18 \%)$ presented with $\mathrm{T} 3 / \mathrm{T} 4$ as compared to 150 patients $(62.76 \%)$ in above 40 years age group. $(P=0.086$, not significant $) 101$ patients $(75.93 \%)$ had positive axillary lymph nodes at presentation in $<40$ years group as compared to 130 patients $(54.39 \%)$ in above 40 group $(P=0.027$, significant).

About $52.63 \%$ of patients received neoadjuvant chemotherapy in $<40$ years group versus $46.86 \%$ in above 40 years group. Estrogen receptor (ER) positivity present in two groups is $39.84 \%$ versus $55.23 \%$, respectively ( $P=0.005$, significant). Patients positive for progesterone receptors (PR) receptors in two groups are $38.54 \%$ versus $44.76 \%(P=0.001$, significant). However, $46.61 \%$ of patients were triple negative in $<40$ years age group versus $32.21 \%$ in above 40 years age group $(P=0.007$, significant $)$.

This is an open access article distributed under the terms of the Creative Commons Attribution-NonCommercial-ShareAlike 3.0 License, which allows others to remix, tweak, and build upon the work non-commercially, as long as the author is credited and the new creations are licensed under the identical terms.

For reprints contact: reprints@ medknow.com

How to cite this article: Sharma D, Singh G. Breast cancer in young women: A retrospective study from tertiary care center of north India. South Asian Cancer 2017;6:51-3. 
Table 1: Characteristics of 373 breast cancer patients: Comparison between two groups

\begin{tabular}{|c|c|c|c|}
\hline & $<40$ & $>40$ & $P$ \\
\hline Patients number & 133 & 239 & \\
\hline \multicolumn{4}{|l|}{ Stage III (\%) } \\
\hline Yes & $88(66.16)$ & $130(54.4)$ & \multirow[t]{2}{*}{0.029} \\
\hline No & $45(33.84)$ & $109(45.6)$ & \\
\hline \multicolumn{4}{|l|}{$\mathrm{T}$ status $(\%)$} \\
\hline $\mathrm{T} 1$ & $6(4.5)$ & $4(1.67)$ & \multirow[t]{4}{*}{0.792} \\
\hline $\mathrm{T} 2$ & $31(23.3)$ & $85(35.56)$ & \\
\hline $\mathrm{T} 3$ & $60(45.11)$ & $75(31.38)$ & \\
\hline $\mathrm{T} 4$ & $36(27.06)$ & $75(31.38)$ & \\
\hline \multicolumn{4}{|l|}{ Nodal status (\%) } \\
\hline N0 & $32(24.06)$ & $87(36.4)$ & \multirow[t]{4}{*}{0.659} \\
\hline N1 & $74(55.63)$ & $93(38.91)$ & \\
\hline N2 & $26(19.54)$ & $57(23.84)$ & \\
\hline N3 & $1(0.75)$ & $2(8.36)$ & \\
\hline \multicolumn{4}{|l|}{ Nodal positive (\%) } \\
\hline Yes & $101(75.93)$ & $154(64.43)$ & \multirow[t]{2}{*}{0.027} \\
\hline No & $32(24.06)$ & $85(35.57)$ & \\
\hline \multicolumn{4}{|l|}{ Metastasis (\%) } \\
\hline M0 & $129(90.97)$ & $231(95.82)$ & \multirow[t]{2}{*}{1} \\
\hline M1 & $4(9.03)$ & $8(4.18)$ & \\
\hline \multicolumn{4}{|l|}{ Surgery $(\%)$} \\
\hline MRM & $126(94.73)$ & $226(94.56)$ & \multirow[t]{4}{*}{1} \\
\hline $\mathrm{BCS}$ & $2(1.5)$ & $3(1.25)$ & \\
\hline Toilet mastectomy & $3(2.25)$ & $4(1.67)$ & \\
\hline None & $2(1.5)$ & $6(2.5)$ & \\
\hline \multicolumn{4}{|l|}{ Chemotherapy (\%) } \\
\hline Neoadjuvant & $70(52.63)$ & $112(46.86)$ & \multirow[t]{3}{*}{0.23} \\
\hline Adjuvant & $59(44.37)$ & $124(51.88)$ & \\
\hline Palliative & $4(3.0)$ & $3(1.25)$ & \\
\hline \multicolumn{4}{|c|}{ Type of chemotherapy (\%) } \\
\hline Anthracycline based & $58(43.6)$ & $121(50.62)$ & \multirow[t]{3}{*}{0.21} \\
\hline Taxane based & $73(54.88)$ & $115(48.11)$ & \\
\hline Others & $2(1.50)$ & $03(1.25)$ & \\
\hline \multicolumn{4}{|l|}{ Margin status (\%) } \\
\hline Positive & $16(12)$ & $29(12.13)$ & \multirow[t]{3}{*}{0.874} \\
\hline Negative & $102(76.7)$ & $182(76.15)$ & \\
\hline Not specified & $15(11.3)$ & $28(11.71)$ & \\
\hline Grade $(\%)$ & & & \\
\hline I & $9(6.76)$ & $24(10.04)$ & 0.846 \\
\hline II & $44(33.08)$ & $73(30.54)$ & \\
\hline III & $31(23.3)$ & $62(25.94)$ & \\
\hline NS & $49(36.84)$ & $80(33.47)$ & \\
\hline LVI $(\%)$ & & & \\
\hline Positive & $67(50.37)$ & $107(44.765)$ & 0.14 \\
\hline Negative & $46(34.58)$ & $85(35.56)$ & \\
\hline Not specified & $20(15.03)$ & $47(19.66)$ & \\
\hline ER status (\%) & & & \\
\hline Positive & $53(39.84)$ & $132(55.23)$ & 0.005 \\
\hline Negative & $80(60.16)$ & $107(44.76)$ & \\
\hline PR status & & & \\
\hline Positive & $37(27.81)$ & $107(44.76)$ & 0.001 \\
\hline Negative & $96(72.18)$ & $132(55.23)$ & \\
\hline HER2/neu (\%) & & & \\
\hline Positive & $28(21.05)$ & $52(21.75)$ & 0.89 \\
\hline Negative & $105(78.94)$ & $187(78.24)$ & \\
\hline Metastasis & & & \\
\hline Yes & $55(41.35)$ & $76(31.8)$ & 0.07 \\
\hline No & $78(58.64)$ & $163(68.2)$ & \\
\hline
\end{tabular}

Contd $\ldots$
Table 1: Contd...

\begin{tabular}{lccc}
\hline & $<40$ & $>40$ & $P$ \\
\hline Primary site metastasis (\%) & & & \\
Brain & $4(5.12)$ & $7(7)$ & 1 \\
Liver & $5(6.41)$ & $10(10)$ & 1 \\
Lung & $18(23.07)$ & $18(18)$ & 0.069 \\
Bone & $27(34.61)$ & $33(33)$ & 0.1 \\
Locoregional & $18(23.07)$ & $25(25)$ & 0.4 \\
Others & $6(7.69)$ & $7(7)$ & 0.09 \\
Subsequent metastasis (\%) & & & \\
Brain & $15(57.69)$ & $9(32.14)$ & 0.007 \\
Liver & $3(11.53)$ & $4(14.28)$ & 0.71 \\
Lung & $2(7.69)$ & $8(28.57)$ & 0.45 \\
Bone & $5(19.23)$ & $4(14.28)$ & 0.291 \\
Locoregional & 0 & $1(3.57)$ & NA \\
Others & $1(3.84)$ & $2(7.14)$ & 1 \\
\hline MRM=Modified radical mastectomy, BCS=Breast conservation surgery, NA=Not \\
available, LVI=Lymphovascular invasion, ER=Estrogen receptor, PR=Progesterone \\
receptors, HER2=Human epidermal growth factor receptor 2
\end{tabular}

$41.35 \%$ patients developed metastasis/locoregional recurrence in less 40 years age group during follow-up versus $31.8 \%$ patients in above 40 years age group $(P=0.07$, not significant). However, metastasis in triple-negative breast cancer in two groups is almost same $43.85 \%$ versus $43.18 \%$, respectively.

There was 78 primary metastasis in $<40$ years group versus 128 in above 40 years age group. A number of subsequent metastasis in two groups is 26 and 25 , respectively. The majority of patients had metastasis in different sites. In total, 55 patients developed metastasis/recurrence in less 40 group versus 76 patients in above 40 groups $(P=0.071)$.

Metastasis to distant organs was more in a patient of younger age group. $14.28 \%$ of patients, $<40$ years had metastasis to brain versus $6.69 \%$ of women above 40 years $(P=0.025$, significant). It has been found that the no of subsequent brain metastasis in two groups are $57.69 \%$ versus $32.14 \%$ respectively ( $P=0.007$, significant), primary lung metastasis in two groups is $23.07 \%$ versus $18 \%$ respectively $(P=0.069$, not significant) Within a median follow-up period of 26.5 months (2-63 months), tumor relapse occurred in 131 cases, among which 84 cases died, 35 patients $(26.31 \%)$ in under 40 group versus 49 patients $(20.50 \%)$ in above 40 group.

Mean DFS was 24.06 versus 20.33, and median DFS was 15 versus 14 ( $P=0.28$, not significant) in $<40$ and above 40 age group, respectively. The estimated mean OS for the two groups is 38.5 and 40.6 months. The estimated median OS in the two groups is 32 and 41 months, respectively [Figure 1].

\section{Discussion}

Breast cancer in young age is very aggressive and has a worse clinical outcome as compared to that in the older group. ${ }^{[3,4]}$ Poor outcome in young age is due to an advanced presentation at diagnosis (larger $\mathrm{T}$ size and axillary lymph node positivity), a higher grade of differentiation, presence of lymphovascular invasion, lower ER/PR expression, presence of triple negativity. ${ }^{[5-7]}$ In a study by Gajdos et al. demonstrated that patients younger than 36 years had larger tumors, more nodal involvement (50\% vs. $37 \%$ ) and were more likely to be diagnosed with Stage II or III cancer (60\% vs. $43 \%){ }^{[7]}$ In 


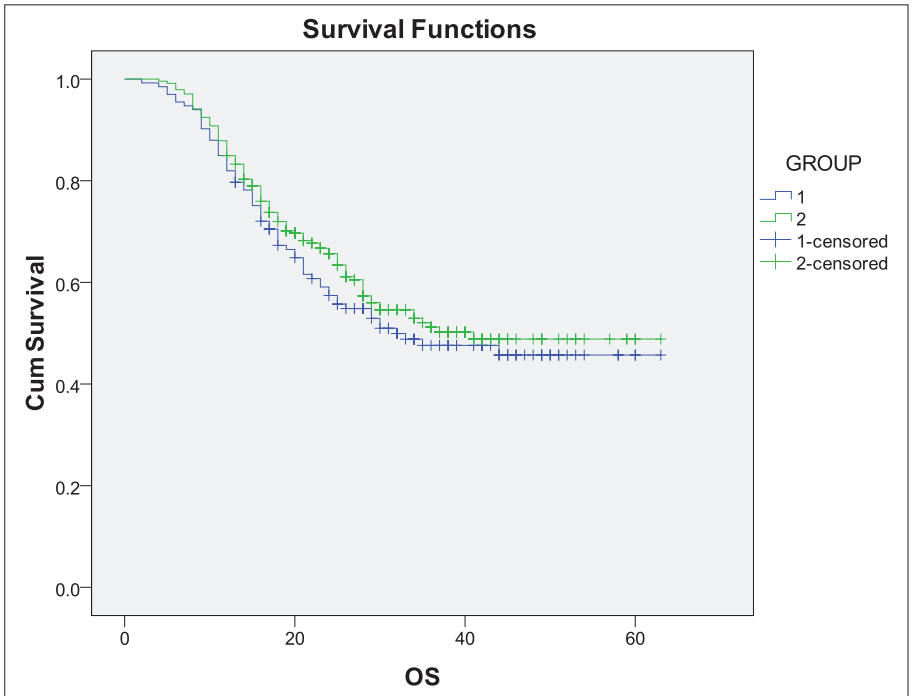

Figure 1: Kaplan-Meier for survival analysis

this present study, also $66.16 \%$ patients in under forty group belong to stage III as compared to $54.4 \%$ patients in above 40 group $(P=0.029$, significant).

Younger age group has been shown to be associated with an increased incidence of ER/PR negativity compared to older patients. ${ }^{[6,8]}$ This study also demonstrated that patients positive for ER and PR receptors in below 40 years age group were $39.84 \%$ and $27.81 \%$ respectively versus $55.23 \%$ and $44.76 \%$ respectively in above 40 years age group. In a study by Carvalho et al. demonstrated that triple negative tumors have also been found to be over-represented in young women with breast cancer, with rates close to $26 \% \cdot{ }^{[8]}$ In this study, also $46.61 \%$ of patients were triple negative in below 40 years age group versus $32.21 \%$ in above 40 years age group.

In this study, locoregional recurrence in the two groups is $13.53 \%$ versus $6.27 \%$, respectively. The analyses of NSABP group trials had also shown that young age is an independent predictor of locoregional recurrence in breast cancer. ${ }^{[9]}$ A study by Bharat et al. estimated the risk of breast cancer recurrence for women diagnosed below the age of 40 to be 1.53 (95\% confidence interval, 1.37-1.74) times higher than in those diagnosed above 40 years. ${ }^{[4]}$

This has been seen that the survival in the young age group is also inferior as compared to older age group. ${ }^{[3,4,9,10]}$ In this study, the median DFS was 15 versus $14(P=0.28$, not significant) in two arms, which may be contributed because of aggressive use of chemotherapy in young age group, especially taxane-based. Gnerlich et al. also showed that young women $<40$ years had a higher breast cancer mortality rate $(18.3 \%$ vs. $12.1 \%, P=0.001)$ than those older than 40 years. ${ }^{[10]}$ In this study, the percentage of expired and lost to follow-up patients is also more in younger age group $49.31 \%$ versus $43.90 \%$.
This study also has a limitation as it is a retrospective study with small sample size. Furthermore, the median follow-up is also very less. The cohort presented in the tertiary center is not the representative of the general population as a whole. In addition, patients came from distant places being a tertiary center; therefore, the percentage of loss to follow-up is high. A larger sample size with a long follow-up may reveal the significant differences between the two groups.

\section{Conclusion}

Many poor prognostic factors have been associated with young age patients with breast cancer as shown by many studies in English Literature as well as above retrospective study from our center, so aggressive management is required to reduce morbidity, mortality, and metastasis in breast cancer presenting at a young age.

\section{Acknowledgment}

We acknowledge the support of record section Department of Radiotherapy and PSM department for statistical analysis.

Financial support and sponsorship

Nil.

\section{Conflicts of interest}

There are no conflicts of interest.

\section{References}

1. Brinton LA, Sherman ME, Carreon JD, Anderson WF. Recent trends in breast cancer among younger women in the United States. J Natl Cancer Inst 2008; 100: 1643-8.

2. Anders CK, Hsu DS, Broadwater G, Acharya CR, Foekens JA, Zhang Y, et al. Young age at diagnosis correlates with worse prognosis and defines a subset of breast cancers with shared patterns of gene expression. J Clin Oncol 2008;26:3324-30.

3. Colzani E, Liljegren A, Johansson AL, Adolfsson J, Hellborg H, Hall PF, et al. Prognosis of patients with breast cancer: Causes of death and effects of time since diagnosis, age, and tumor characteristics. J Clin Oncol 2011;29:4014-21.

4. Bharat A, Aft RL, Gao F, Margenthaler JA. Patient and tumor characteristics associated with increased mortality in young women (<or=40 years) with breast cancer. J Surg Oncol 2009; 100:248-51.

5. Winchester DP, Osteen RT, Menck HR. The National Cancer Data Base report on breast carcinoma characteristics and outcome in relation to age. Cancer 1996;78:1838-43.

6. Anders CK, Fan C, Par C, Parker JS. Breast carcinomas arising at a young age: Unique biology or a surrogate for aggressive intrinsic subtypes? J Clin Oncol 2011;29:e 18-20.

7. Gajdos C, Tartter PI, Bleiweiss IJ, Bodian C, Brower ST. Stage 0 to stage III breast cancer in young women. J Am Coll Surg 2000; 190:523-9.

8. Carvalho FM, Bacchi LM, Santos PP, Bacchi CE. Triple-negative breast carcinomas are a heterogeneous entity that differs between young and old patients. Clinics (Sao Paulo) 2010;65:1033-6.

9. Wapnir IL, Anderson SJ, Mamounas EP, Geyer CE Jr., Jeong JH, Tan-Chiu E, et al. Prognosis after ipsilateral breast tumor recurrence and locoregional recurrences in five National Surgical Adjuvant Breast and Bowel Project node-positive adjuvant breast cancer trials. J Clin Oncol 2006;24:2028-37.

10. Gnerlich JL, Deshpande AD, Jeffe DB, Sweet A, White N, Margenthaler JA. Elevated breast cancer mortality in women younger than age 40 years compared with older women is attributed to poorer survival in early-stage disease. J Am Coll Surg 2009;208:341-7. 